\title{
Airway management of an open penetrating neck injury
}

\author{
Nayer Youssef, MD; Karen E. Raymer, MD, MSc
}

\section{ABSTRACT}

Although penetrating neck injuries (PNIs) represent a small subset of patients presenting to the emergency department (ED), they can result in significant morbidity and mortality. The approach to airway management in PNI varies widely according to clinical presentation and local practice, such that global management statements are lacking. Although rapid sequence intubation (RSI) may be safe in most patients with $\mathrm{PNI}$, the high-risk subset $(10 \%)$ of patients with laryngotracheal injury require particularly judicious airway management. It is not known if RSI is safe in such patients, nor has there been reported use of videolaryngoscopy in patients with open PNI. Established principles of airway management in patients with an open airway injury include the avoidance of both positive pressure bag-mask ventilation and blind tube passage and the early consideration of a surgical airway. Because this high-risk subset may not be clinically apparent on initial presentation in the ED, such guiding principles apply to all patients with PNI until the nature of the injury is more accurately defined. In this report, we present the case of a patient who presented to the ED with a zone II open PNI, which occurred as a result of a stab wound.

\section{RÉSUMÉ}

Bien que les plaies pénétrantes du cou (PPC) représentent un faible pourcentage des cas traités dans les services d'urgence (SU), elles peuvent néanmoins entraîner une forte morbidité et une forte mortalité. Les interventions en vue du maintien de la perméabilité des voies aériennes dans les cas de PPC varient énormément selon le tableau clinique et les pratiques locales, au point que les déclarations sur la prise en charge générale manquent. Si l'intubation en séquence rapide (ISR) est sans danger chez la plupart des patients souffrant d'une PPC, le maintien de la perméabilité des voies aériennes dans le sous-groupe de patients à risque élevé (10\%) présentant des lésions laryngotrachéales exige des interventions particulièrement judicieuses. On ne sait pas si I'ISR est sûre chez ces patients, et la documentation ne fait pas état non plus de l'utilisation de la vidéolaryngoscopie chez les patients souffrant d'une PPC béante. Les principes déjà établis du maintien de la perméabilité des voies aériennes dans les cas de blessure béante des voies aériennes comprennent le non-recours à la ventilation par masque et ballon à pression positive et à l'intubation à l'aveugle ainsi que la possibilité d'une ouverture chirurgicale précoce des voies aériennes. Comme les lésions dans ce sous-groupe de patients à risque élevé peuvent être non décelables cliniquement à la première consultation au SU, ces principes de conduite s'appliquent à tous les blessés présentant une PPC jusqu'à ce que la nature du trauma soit davantage précisée. Sera exposé ici le cas d'une patiente traitée au SU pour une PPC béante de la zone II, par suite d'une agression à I'arme blanche.

Keywords: airway management, cut throat, neck injury, penetrating neck injury, trauma

Penetrating neck injuries (PNIs), injuries disrupting the platysma muscle layer, are uncommon traumatic injuries; however, they are associated with a high morbidity and mortality due to the complex anatomy and vital nature of the structures involved. Airway management carries some unique considerations. Depending on the availability of other specialists, the emergency physician may assist or lead airway management in this setting. In this report, we present the case of a stab wound resulting in a zone II PNI causing transection of the larynx, pharynx, left external jugular vein, and branches of the left external carotid artery. Considerations for airway management in PNI are discussed.

\section{CASE PRESENTATION}

A 49-year-old female patient with a stab wound to the neck was transferred to the emergency department

From the Department of Anesthesiology, McMaster University, Hamilton, ON.

Correspondence to: Dr. Karen E. Raymer, Department of Anesthesiology, McMaster University, 1200 Main Street West, HSC-2U1, Hamilton, ON L8N 3Z5; karenraymer@cogeco.ca.

This article has been peer reviewed. 
(ED) by emergency medical service (EMS). The time from injury to arrival of EMS was unknown. Blood loss at the scene was estimated to be 3 litres. The time from first EMS encounter to arrival at the ED was 8 minutes. Prehospital interventions included application of pressure dressing, securing of intravenous access with administration of normal saline bolus, and the delivery of oxygen by a nonrebreather facemask.

ED staff was alerted by EMS approximately 5 minutes prior to the patient's arrival. During that time, the trauma team was assembled, and the on-call anesthesiologist and ear, nose, and throat surgeon were called in. Difficult airway equipment and rapid-volume infusers were prepared. On arrival at the ED, the patient was conscious and had vital signs as follows: blood pressure (BP) of 70/40 mm Hg, heart rate (HR) of 130 beats/min, and oxygen saturation $\left(\mathrm{SpO}_{2}\right)$ of 67\%. A deep, horizontal neck laceration, approximately $15 \mathrm{~cm}$ in width (Figure 1), was compressed using a large dressing. The patient was in severe respiratory distress, with clinical features of upper airway obstruction. Blood emanated from both the neck wound and mouth.

Due to the location and depth of the neck wound and impending loss of the airway, immediate control of the airway was required. In addition, other urgent needs included bleeding control, surgical exploration, and wound repair. Direct laryngoscopy revealed no recognizable anatomy due to the presence of blood and anatomic distortion of the upper airway. Sedation was avoided due to the patient's precarious hemodynamic

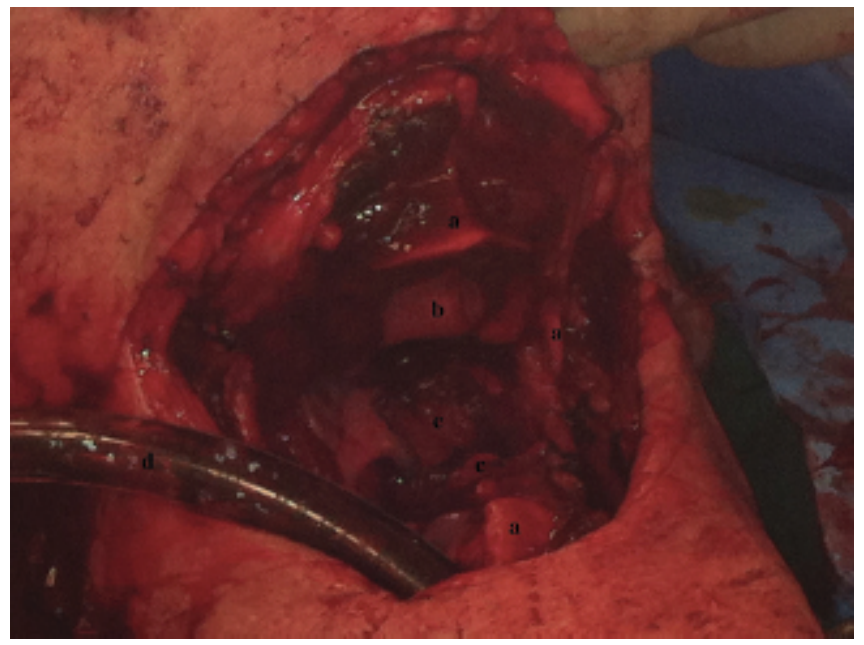

Figure 1. Endotracheal tube inserted through the transected larynx. $A$, Thyroid cartilage. $B$, Epiglottis. $C$, Posterior pharyngeal wall. $D$, Endotracheal tube. state and compromised upper airway. The patient did not resist the attempt at direct laryngoscopy or any subsequent interventions. Although the precise nature of the airway injury was unknown at that time, it was felt that orotracheal intubation was unlikely to be successful within a satisfactory timeframe (regardless of technique). Preparations were made to explore the neck for airway access. Suctions, surgical clamps, and a cricothyroidotomy kit were readied prior to the removal of wound pressure. With blood flooding the field, air bubbles emanated from the transected laryngeal opening, and a size 7.5 endotracheal tube (ETT) was readily inserted into the trachea through the neck wound via the transected larynx (see Figure 1). With mechanical ventilation, oxygen saturation improved to $100 \%$. Appropriate ETT position was confirmed with a colorimetric carbon dioxide detector and a chest $\mathrm{x}$-ray, with the latter also ruling out hemopneumothorax. Clamps were applied to the open vessels in the neck wound. A size 9 French femoral venous catheter was inserted to facilitate volume resuscitation using rapid-infusion warming devices. In the ED, 8 units of uncrossed-matched packed red blood cells ( $\mathrm{O}$ negative) and 4 units of fresh frozen plasma (group $\mathrm{AB}$ ) were transfused.

With improved vital signs (BP 90/60 $\mathrm{mm} \mathrm{Hg}, \mathrm{HR}$ 120 beats/min, $\mathrm{SpO}_{2} 100 \%$ ) and without evidence of other life-threatening injuries, the patient was transferred to the operating room (OR) for surgical management 26 minutes after arriving at the ED.

In the OR, the clamped vessels were explored, resulting in the ligation of the left superior thyroid branch of the left external carotid artery, as well as multiple superficial veins, including the left external jugular vein. A tracheostomy was performed below the level of the injury. Bronchoscopy ruled out endotracheal or endobronchial injuries. Exploration of the neck confirmed a $15 \mathrm{~cm}$ horizontal zone II laceration ( $5 \mathrm{~cm}$ in depth) transecting the thyroid cartilage at the level of the glottis with extension through the posterior pharynx into the prevertebral fascia. There was complete transection of both the pharynx and the larynx. The aerodigestive tract was reconstructed circumferentially using a combination of interrupted and running sutures (Figure 2).

The patient was hemodynamically stable throughout the course of the 5 -hour procedure. A total of 13 units of packed red blood cells, 9 units of fresh frozen plasma and 4 units of platelets was transfused in the OR and 


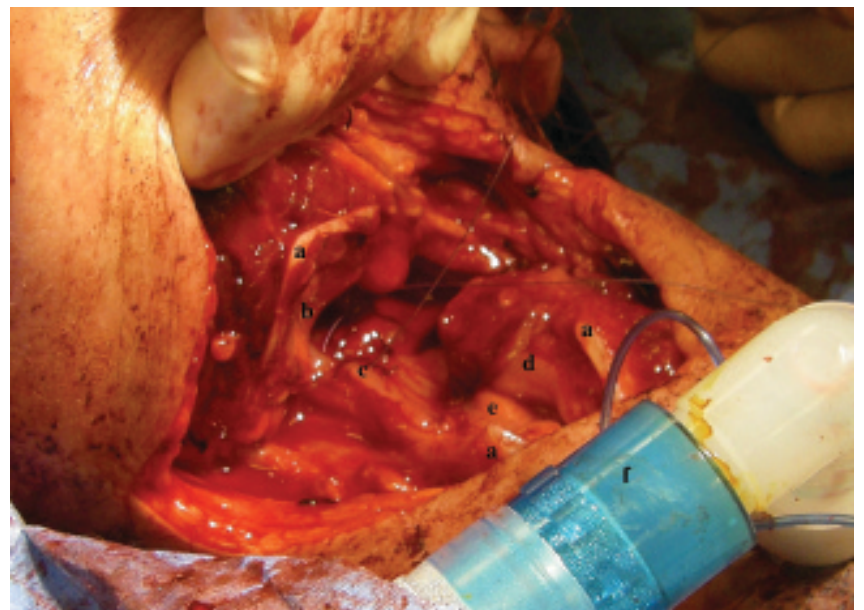

Figure 2. Surgical exploration and repair of transected aerodigestive tract. $A$, Thyroid cartilage. $B$, Epiglottis. $C$, Posterior pharyngeal wall. $D$, Left vocal fold. $E$, Right vocal fold. $F$, Anesthetic circuit connected to the tracheostomy tube.

ED. The patient was weaned from mechanical ventilation 3 days postoperatively. Prior to discharge, she was able to swallow and phonate with the tracheostomy corked, although with significant hoarseness.

\section{DISCUSSION}

The prevalence of PNI (as a percentage of trauma presentations in adults) is variable according to the population studied, ranging from less than 1 to $10 \% .^{1-3}$ PNI can result from stab wounds, gunshots, or, less commonly, trauma due to other sharp objects, such as glass. In the United States, PNI comprises about $1 \%$ of all trauma patients. ${ }^{4}$ A single-centre review suggests that PNIs are less common in Canadian major trauma centres (about 0.5\%), which may reflect the comparatively lower rate of violent crime. ${ }^{3}$ In a systematic review involving over 2,400 patients with PNI, McConnell and Trunkey reported that the vital structures involved in such injuries included the trachea (10\%), esophagus (9.6\%), internal jugular veins (9\%), and carotid arteries $(6.7 \%){ }^{5}$ Overall mortality in patients with PNI ranges from 3 to $10 \% .{ }^{6,7}$ Mortality is even higher when PNI includes penetrating laryngotracheal trauma $(20 \%)$ or pharyngoesophageal injuries (22\%). ${ }^{8-10}$

When discussing PNI, standardized nomenclature divides the neck into three anatomic zones. Zone I extends from the thoracic inlet to the cricoid cartilage. Zone II extends from the cricoid cartilage to the mandibular angle and is the frequent site of PNI.
Zone III is located between the mandibular angle and the skull base. The nomenclature carries implications for surgical management as zone I and III injuries are less accessible to surgical exploration. Zone II generally confers a lower mortality due to the ready access for surgical exploration, as well as the ability to control hemorrhage with direct pressure. ${ }^{11}$ Although historically surgical exploration was recommended for all zone II PNIs, it has been shown more recently that conservative evaluation with panendoscopy and arteriography is appropriate in selected cases. ${ }^{12}$ In contrast, the airway management of PNI is guided by clinical presentation rather than by zone. The principles of airway management in PNI are highlighted in the context of the available literature.

Prehospital management of patients with PNI should reflect a "load and go" philosophy as attempts at endotracheal intubation will delay definitive care and may be deleterious. ${ }^{13}$ Once in the ED, indications for early intubation include respiratory distress or signs of significant airway injury, including subcutaneous emphysema, airway obstruction, significant bleeding or hematoma, and change of voice and stridor. ${ }^{14-16}$

Although bag-mask ventilation (BMV) is an important tool to be used in the trauma setting pending definitive airway management, ${ }^{17}$ in the presence of PNI, BMV may force air into the soft tissue planes. Resultant intra- and/or extraluminal tension may lead to further anatomic distortion, disruption, or obstruction of the airway. Cervical spine injuries are uncommon in PNI, and routine immobilization may hinder management by impeding visualization of the airway or obscuring other injuries. The literature suggests that spinal immobilization should be considered only in cases of PNI when the mechanism of injury and/or physical findings suggest spinal cord involvement. ${ }^{18-23}$

Rapid sequence intubation (RSI) can be considered in cases where the airway is felt to be threatened but normal anatomy and structure relationship are well preserved. ${ }^{18,24,25}$ In a retrospective study of more than 700 patients with PNI, Mandavia and colleagues found RSI to be safe and effective, with all of the 39 patients successfully intubated in this manner, compared to awake fibre-optic intubation, which was successful in 9 of 12 patients (three failures being rescued with RSI)..$^{24}$ Although the results of this study would seem to support the safety of RSI in PNI, they may not apply to the $10 \%$ of patients with PNI who have a primary airway injury, ${ }^{5}$ a subset that may not be identified on 
initial presentation. A much smaller review performed at a Canadian tertiary trauma centre revealed variability in airway management in PNI. ${ }^{3}$ Of 19 patients with PNI, 16 required intubation, with RSI and awake fibre-optic bronchoscopy each being used in eight instances. This would support others' assertion that the optimal airway technique in patients with PNI varies according to clinical presentation, technical skills, and hospital resources. ${ }^{3}$

The option of awake fibre-optic intubation is appealing in that it maintains spontaneous respiration in a setting where the precise nature of the airway injury is undetermined and allows for the careful examination of the injury during intubation. This technique is limited by the patient's level of cooperation and ability to tolerate the procedure. ${ }^{26}$ Furthermore, visualization through the bronchoscope may be difficult if there is blood in the airway, and availability of equipment in the ED may be a limiting factor.

Blind nasal intubation has been reported in the setting of PNI, ${ }^{7,27}$ although it lacks support due to the possibility of causing further airway injury or bleeding. ${ }^{28,29}$

The use of a gum elastic bougie for a patient with PNI and tracheal injury has been described in the emergency medicine literature. ${ }^{11}$ Although this report described its successful use, the authors cautioned that as a blind technique, it carries the risk of tracheal transection, and they recommend the use of fibre-optic bronchoscopy, where possible, to visualize (and avoid extending) intraluminal injuries.

Videolaryngoscopy has been shown to improve the laryngoscopic view and the rate of successful emergency intubations in the ED compared to direct laryngoscopy. ${ }^{30}$ There is no description of videolaryngoscopy use in PNI, nor is it obvious that videolaryngoscopy would overcome the difficulties associated with blood and anatomic distortion. The rigid stylet used with videolaryngoscopes may extend the traumatic airway disruption if it advances through the glottis beyond the limits of visual monitoring.

When PNI has resulted in a significant primary airway injury, including an open airway, as in the present case, the grounding principle is that the (endo)tracheal tube should be advanced with visual guidance until it has passed the site of injury. Although oral endotracheal intubation may be achievable, the surgical airway represents the standard approach and should not be delayed by persistent attempts at a supraglottic airway. The value of surgical airway in PNI management of zone II injuries is highlighted in the literature, ${ }^{31}$ although it carries the risk of disrupting a stable hematoma and worsening bleeding. ${ }^{32}$ When PNI results in partial or complete tracheal transection, insertion of an ETT directly into the caudal end of the exposed trachea should be considered a lifesaving maneuver. ${ }^{33}$ If needed, a clamp can be used to stabilize the caudal end of the trachea.

\section{CONCLUSION}

In patients with PNI, early intubation is indicated when respiratory distress or evidence of airway injury is present. Available studies, indicating a wide range of airway management practices, suggest that RSI is safe in most patients with PNI. Although only $10 \%$ of patients with PNI have a disrupted airway, their presentation may not be immediately obvious in the ED. In this subset of patients, principles of management include avoiding extension of the injury due to passing a tube beyond the limits of visual guidance. An awake fibre-optic intubation requires a stable and cooperative patient. The surgical airway remains the standard management for the patient with laryngotracheal disruption and should not be delayed by persistent attempts at supraglottic endotracheal intubation. Direct introduction of an ETT through the neck wound should be considered early if the airway is transected. Finally, the coordination of the appropriate services, including ED, anesthesia, ear, nose, and throat and general surgery, and intensive care, is a key feature of the successful management of these challenging patients.

Acknowledgement: We thank James E. Paul, MD, MSc, (Associate Clinical Professor, Department of Anesthesiology, McMaster University) and Brian J. Colborne, MD, CCFP(EM) (Department of Emergency Medicine, Brantford General Hospital, Brantford, ON) for reviewing the manuscript. Appreciation is extended to James E.M. (Ted) Young, BSc, MD, FRCSC (Clinical Professor, Department of Surgery, McMaster University) for his assistance with the figures.

Competing interests: None declared.

\section{REFERENCES}

1. Demetriades D, Skalkides J, Sofianos C, et al. Carotid artery injuries: experience with 124 cases. 7 Trauma 1989;29:91-4, doi:10.1097/00005373-198901000-00019. 
2. Pakarinen TK, Leppaniemi A, Sihvo E, et al. Management of cervical stab wounds in low volume trauma centres: systematic physical examination and low threshold for adjunctive studies, or surgical exploration. Injury 2006;37: 440-7, doi:10.1016/j.injury.2006.01.044.

3. Tallon JM, Ahmed JM, Sealy B. Airway management in penetrating neck trauma at a Canadian tertiary trauma centre. CFEM 2007;9:101-4.

4. Demetriades D, Theodorou D, Cornwell E 3rd, et al. Penetrating injuries of the neck in patients in stable condition. Physical examination, angiography, or color flow Doppler imaging. Arch Surg 1995;130:971-5, doi:10.1001/ archsurg.1995.01430090057019.

5. McConnell DB, Trunkey DD. Management of penetrating trauma to the neck. Adv Surg 1994;27:97-127.

6. Bell RB, Osborn T, Dierks EJ, et al. Management of penetrating neck injuries: a new paradigm for civilian trauma. F Oral Maxillofac Surg 2007;65:691-705, doi:10. 1016/j.joms.2006.04.044.

7. Weitzel N, Kendall J, Pons P. Blind nasotracheal intubation for patients with penetrating neck trauma. 7 Trauma 2004; 56:1097-101, doi:10.1097/01.TA.0000071294.21893.A4.

8. Asensio JA, Berne J, Demetriades D, et al. Penetrating esophageal injuries: time interval of safety for preoperative evaluation-how long is safe? 7 Trauma 1997;43:319-24, doi:10.1097/00005373-199708000-00018.

9. Bryant AS, Cerfolio RJ. Esophageal trauma. Thorac Surg Clin 2007;17:63-72, doi:10.1016/j.thorsurg.2007.02.003.

10. Demetriades D, Asensio JA, Velmahos G, et al. Complex problems in penetrating neck trauma. Surg Clin North Am 1996;76:661-83, doi:10.1016/S0039-6109(05)70475-8.

11. Steinfeldt J, Bey TA, Rich JM. Use of a gum elastic bougie (GEB) in a zone II penetrating neck trauma: a case report. 7 Emerg Med 2003;24:267-70, doi:10.1016/S0736-4679(02) 00749-7.

12. Tisherman SA, Bokhari F, Collier B, et al. Clinical practice guideline: penetrating zone II neck trauma. 7 Trauma 2008; 64:1392, doi:10.1097/TA.0b013e3181692116.

13. Demetriades D, Theodorou D, Cornwell EE, et al. Evaluation of penetrating injuries of the neck: prospective study of 223 patients. World 7 Surg 1997;21:41-8, doi:10. 1007/s002689900191.

14. Bent JP 3rd, Silver JR, Porubsky ES. Acute laryngeal trauma: a review of 77 patients. Otolaryngol Head Neck Surg 1993;109: 441-9.

15. Eggen JT, Jorden RC. Airway management, penetrating neck trauma. 7 Emerg Med 1993;11:381-5, doi:10.1016/ 0736-4679(93)90238-3.

16. Minard G, Kudsk KA, Croce MA, et al. Laryngotracheal trauma. Am Surg 1992;58:181-7.

17. Stockinger ZT, McSwain NE Jr. Prehospital endotracheal intubation for trauma does not improve survival over bagvalve-mask ventilation. I Trauma 2004;56:531-6, doi:10. 1097/01.TA.0000111755.94642.29.

18. Brywczynski JJ, Barrett TW, Lyon JA, et al. Management of penetrating neck injury in the emergency department: a structured literature review. Emerg Med 7 2008;25:711-5, doi:10.1136/emj.2008.058792.

19. Inaba K, Barmparas G, Ibrahim D, et al. Clinical examination is highly sensitive for detecting clinically significant spinal injuries after gunshot wounds. 7 Trauma 2011;71: $523-7$

20. Lustenberger T, Talving P, Lam L, et al. Unstable cervical spine fracture after penetrating neck injury: a rare entity in an analysis of 1,069 patients. 7 Trauma 2011;70:870-2, doi:10.1097/TA.0b013e3181e7576e.

21. Rhee P, Kuncir EJ, Johnson L, et al. Cervical spine injury is highly dependent on the mechanism of injury following blunt and penetrating assault. 7 Trauma 2006;61:1166-70, doi:10.1097/01.ta.0000188163.52226.97.

22. Stuke LE, Pons PT, Guy JS, et al. Prehospital spine immobilization for penetrating trauma-review and recommendations from the Prehospital Trauma Life Support Executive Committee. 7 Trauma 2011;71:763-9; discussion 769-70, doi:10.1097/TA.0b013e3182255cb9.

23. Vanderlan WB, Tew BE, Seguin CY, et al. Neurologic sequelae of penetrating cervical trauma. Spine (Phila Pa 1976) 2009;34:2646-53, doi:10.1097/BRS.0b013e3181bd9df1.

24. Mandavia DP, Qualls S, Rokos I. Emergency airway management in penetrating neck injury. Ann Emerg Med 2000;35:221-5, doi:10.1016/S0196-0644(00)70071-0.

25. Walls RM. Airway management. Emerg Med Clin North Am 1993;11:53-60.

26. Huh H, Han JH, Chung JY, et al. Anesthetic management of penetrating neck injury patient with embedded knife-a case report. Korean 7 Anesthesiol 2012;62:172-4, doi:10.4097/ kjae.2012.62.2.172.

27. Shearer VE, Giesecke AH. Airway management for patients with penetrating neck trauma: a retrospective study. Anesth Analg 1993;77:1135-8, doi:10.1213/00000539-19931200000009 .

28. Ligier B, Buchman TG, Breslow MJ, et al. The role of anesthetic induction agents and neuromuscular blockade in the endotracheal intubation of trauma victims. Surg Gynecol Obstet 1991;173:477-81.

29. Shrager JB. Tracheal trauma. Chest Surg Clin N Am 2003;13: 291-304, doi:10.1016/S1052-3359(03)00004-8.

30. Sakles JC, Mosier J, Chiu S, et al. A comparison of the CMAC video laryngoscope to the Macintosh direct laryngoscope for intubation in the emergency department. Ann Emerg Med 2012;60:739-48, doi:10.1016/j.annemergmed. 2012.03.031.

31. Ezeanolue BC. Management of the upper airway in severe cut-throat injuries. Afr 7 Med Med Sci 2001;30:233-5.

32. Rathlev NK, Medzon R, Bracken ME. Evaluation and management of neck trauma. Emerg Med Clin North Am 2007;25:679-94, viii, doi:10.1016/j.emc.2007.06.006.

33. Mussi A, Ambrogi MC, Ribechini A, et al. Acute major airway injuries: clinical features and management. Eur 7 Cardiothorac Surg 2001;20:46-51, discussion 51-2, doi:10. $\underline{1016 / S 1010-7940(01) 00702-3}$. 